\title{
Contexto regional y migraciones a la frontera sur de México
}

\author{
Manuel Ángel Castillo G. \\ EL COLEGIO DE MÉxICO
}

INTRODUCCIÓN: CARÁCTER SOCIAL E HISTÓRICO DE LAS MIGRACIONES

\section{L}

as migraciones, entendidas como el desplazamiento más o menos permanente de grupos de población de su lugar de residencia habitual, constituyen un fenómeno social. Significa que el momento, la forma $y$ las condiciones en que ocurren están íntimamente vinculados al contexto en el que se desarrollan, ${ }^{1}$ como también a los procesos que operan en esos ámbitos; esto es, que no son ajenos al medio que rodea a las personas

\footnotetext{
${ }^{1}$ De manera simple y esquemática, ese contexto se refiere al lugar de origen, la trayectoria del desplazamiento y el lugar de destino de tales movilizaciones.
}

y que tampoco la decisión de emigrar, trascendental en la vida de personas, familias y pueblos, es una decisión individual desligada del mundo que los circunda.

Históricamente las migraciones han sido provocadas por diversos factores - de carácter económico, político, social y/o cultural- y, en la mayoría de los casos, por una estrecha y compleja interrelación de algunos de ellos. Una de las principales preocupaciones de los estudiosos de los fenómenos migratorios es precisamente la determinación de tales factores. De manera bastante simplista, se puede decir que sus esfuerzos están encaminados a poner de relieve los llamados factores de "atracción" y de "expulsión".

Las migraciones en el interior de un 


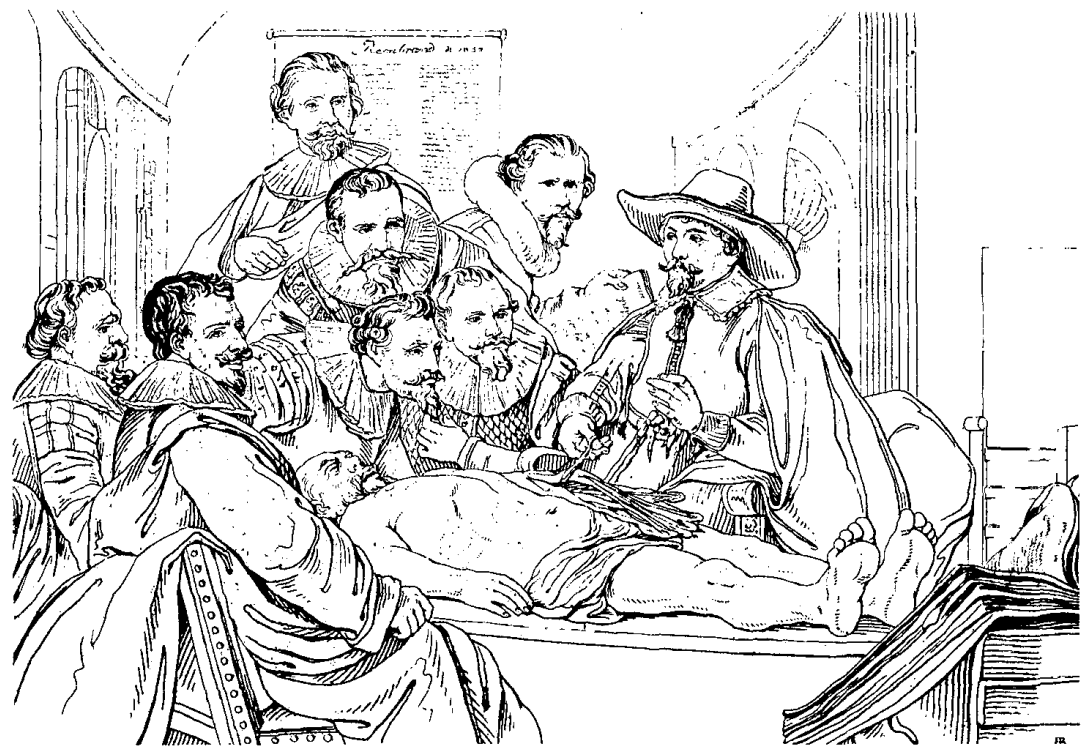

país son, en general, fenómenos que alteran la dinámica social en un grado relativamente restringido, por cuanto se supone que se originan por causas que son provocadas internamente y porque, a la vez, generan efectos de alcances también internos; de esa cuenta, la atención de sus causas y efectos es un problema de responsabilidad y soberanía internas, aunque, en algunos casos, parte de sus determinantes se remitan también a factores externos.

México es un país con una historia en este tipo de migraciones: los procesos de colonización de territorios "vacióos" (selváticos, fronterizos, etc.), la concentración en las gran- des zonas metropolitanas, el flujo de trabajadores temporales a ciertas zonas de actividad agrícola, etc., dan cuenta de esta experiencia. Algunos de estos desplazamientos y sus efectos han sido considerados como negativos, pero no podemos negar que, en determinadas circunstancias, los movimientos de población han sido y son procesos indispensables para el desarrollo de regiones y actividades productivas, así como también para el cumplimiento de objetivos nacionales (de descentralización, de identidad cultural, de consideraciones estratégicas, etcétera).

Por su parte, en la vecina región centroamericana, como producto de 
las situaciones vividas en los últimos tiempos, han ocurrido desplazamientos forzosos internos, cuyo origen, pero también su ocurrencia, han sido esencialmente negativos, tanto para la población involucrada directamente como para las regiones afectadas. Por su origen, dimensión y características han llamado la atención de la comunidad internacional, lo que ha motivado la preocupación no sólo de organismos nacionales, sino también de foros e instituciones que pertenecen a aquélla.

Mientras tanto, los movimientos de población que cruzan límites internacionales tienen efectos directos sobre pueblos y gobiernos con distintas formas de organización y antecedentes históricos. A la vez, constituyen parte esencial del marco de las relaciones entre los países involucrados. Por ello, el tema migratorio forma una parte, cada vez más importante, de las agendas de las reuniones entre diversas instancias de gobiernos vecinos (ejecutivos, parlamentarios, etc.). Asimismo, su influencia y la forma de enfrentar sus efectos son elementos multinacionales; como consecuencia de ello se han creado y desarrollado organismos internacionales -gubernamentales y no gubernamentales-específicamente orientados a su atención (es el caso del ACNUR, por ejemplo).

México ha sido y continúa siendo importante origen de migraciones hacia el exterior. A la vez, desde hace muchos años ha sido ámbito de re. cepción de varios y en ocasiones importantes flujos de población que se han internado en su territorio bajo distintas modalidades, impulsados por una diversidad compleja de motivacio. nes y orientados por una amplia gama de propósitos.

\section{EL CONTEXTO REGIONAL Y \\ LA COYUNTURA ACTUAL}

El origen de las migraciones que tra. dicionalmente han cruzado la frontera sur de México se ubica principalmente en los países centroamericanos y, en particular, ellas han procedido de la vecina república de Guatemala. ${ }^{2}$ Esta importancia se explica, en un primer momento, por la vecindad geográfica, pero no así la diversidad de moda. lidades, como tampoco las variaciones en intensidad observadas históricamente. Es evidente también que el desigual grado de desarrollo social y económico es un factor que, en este caso, opera secularmente como factor de movilización de ciertos sectores originarios de esos países.

Desde fines de la década de los setenta, la región centroamericana se ha convulsionado en una amplia y profunda crisis de orden generalizado. A las extremas y crónicas desigualdades sociales de carácter estructural, se ha sumado el hecho de que, en al me-

2 Aclaramos que se trata de los flujos tradicionales, puesto que, en el presente siglo, México acogí́ grupos significativos de perseguidos políticos procedentes de países que experimentaron situaciones específicas de crisis, como fue el caso de la República Española, Argentina, Chile, etc. Por otra parte, en los últimos años, a las corrientes migratorias centroamericanas se han adicionado personas de otras nacionalidades (sudamericanas, caribeñas e incluso asiáticas) que por esa vía buscan cruzar el territorio mexicano para llegar a Estados Unidos. 
nos tres de los países, se han producido conflictos armados que, directa o indirectamente, han involucrado a población civil no combatiente, la cual ha tenido que buscar refugio en resguardo de su vida y seguridad personales.

La explicación de estas situaciones extremas nos remite esencialmente a la secular imposibilidad de solucionar las ingentes demandas de carácter económico, social, político y cultural, de sus pueblos. Ello es así, sobre todo, por la intolerancia de los regímenes y de los grupos de poder que han predominado en los países de la región y que, consecuentemente, han dado lugar a la persistente prevalencia de situaciones de pobreza extrema de amplios sectores de sus respectivas poblaciones. Los efectos de tales enfrentamientos se extendieron no sólo al resto de los países de la región, sino que incluso se han desbordado a terceros países.

Uno de dichos efectos lo constituyen las migraciones "forzadas", tanto de familias como de comunidades enteras, así como también las que, provocadas de una manera más indirecta, se han materializado en intensos flujos migratorios, tanto dentro como fuera de la región. Nuestro trabajo se propone más adelante contribuir a sustentar esta aseveración.

En este contexto, la política exterior de México ha sido sumamente activa y se ha propuesto como objetivo la búsqueda de mecanismos que conduzcan a la solución pacífica del conflicto político. Su participación en el Grupo de Contadora, en el Grupo de los Ocho y en la Comisión Internacio- nal de Verificación y Seguimiento (en el marco de los acuerdos de Esquipulas) asi lo ratifican.

En ese sentido, los planteamientos del gobierno mexicano y de los países con los que ha coincidido se han sustentado en la creencia de que, para lograr el objetivo de pacificación de la región, es necesario tener en cuenta, sobre todo, el origen de la situación de inestabilidad. Esto significa considerar el rezago en materia de desarrollo y las desigualdades sociales, los cuales se expresan en amplios niveles de pobreza de la población.

Por su parte, México ha recibido -parcialmente, debido a su vecindad geográfica- diversos impactos motivados por esta situación inestable. Por un lado, no se puede negar que la compleja situación de crisis afecta todos los ámbitos de las relaciones con los países de la región, bilateral o multilateralmente (productivas, comerciales, culturales, etc.). Pero por otro, y en lo que a nosotros concierne, cl país ha consolidado su carácter de destino de flujos de población que se movilizan en busca de mejores condiciones de trabajo y de vida (entiéndase por estas últimas incluso la conservación de la misma), así como de zona de paso de otros que se dirigen a destinos más lejanos con propósitos semejantes.

Es por ello que México ha enfrentado una clura prueba al encarar una situación que, al menos hasta fines de la década de los ochenta, le era desconocida. Hay que reconocer que el incremento acelerado en canticlad y grado de diversidad de los migrantes -muchos de ellos indocumentados$y$, posteriormente, la llegada ma- 
siva de refugiados guatemaltecos, lo sorprendieron. ${ }^{3}$ Las reacciones iniciales de funcionarios, dependencias $\mathrm{e}$ incluso de la sociedad civil fueron heterogéneas y algunas de ellas desconcertantes. A la larga tradición mexicana de respeto y práctica activa de otorgamiento del derecho de asilo se han contrapuesto posturas, $e$ incluso acciones, xenofóbicas, de persecución y algunas también, por qué no decirlo, atentatorias de los derechos humanos. ${ }^{4}$

No obstante los esfuerzos por la pacificación de la región, la situación de conflicto persiste hasta la fecha. A ello han contribuido las diversas fuerzas que, en el interior de los países y desde diversas posiciones de poder, se oponen a las necesarias transformaciones sociales que tendrían que modificar la esencia del conflicto. Pero además, se ha sumado la acción de agentes y gobiernos externos que apoyan tales posiciones, no sólo desde una perspec-

3 Probablemente el caso de los refugiados ha sido el más espinoso de los experimentados, puesto que a las condiciones en que ocurrio (el drama humano que significaba la llegada masiva de personas, familias y comunidades en condiciones deplorables de salud, alimentación, terror, etc.) se sumó el ambiente de presiones de todo tipo que ejerció el gobierno guatemalteco, que en algunos casos llegó a polarizar las opiniones en el ámbito interno y además puso en grave riesgo las relaciones entre los dos países. Internamente, esta siruación contribuyó a diversificar las posiciones entre diversos sectores de la sociedad y dio pie a argumentar que tenía que enfocarse desde la perspectiva de la "seguridad nacional".

4 Ello ba sido ampliamente denunciado y documentado, sobre todo por organismos no gubernamentales, medios de comunicación y, eventualmente, por los propios afectados. tiva fincada en una afinidad de intereses con los grupos de poder local, sino también con base en prácticas intervencionistas sustentadas en el argumento de la protección de intereses estratégicos continentales.

Así, la década de los ochenta ha sido escenario de intensas confrontaciones en el interior de los países de la región. El enfrentamiento político fue rebasado por el de carácter militar. Por ello, la posición mediadora de los países externos a la región centroamericana se orientó a la búsqueda del necesario diálogo y la reconciliación nacionales. Un buen número de los procesos electorales realizados han sido cuestionados por su carácter restringido (por limitaciones legales o de fuerza) y relativo (por su inserción en el contexto de francas situaciones de guerra). La evolución reciente de los acontecimientos, principalmente a raíz de los resultados de las elecciones en Nicaragua, podría sugerir un cambio en la región en materia de la dinámica de los conflictos y de las situaciones de crisis generalizada. Sin embargo, no existen suficientes elementos -por el momento-para confirmar tal presagio. ${ }^{5}$ Los efectos de largo plazo de la economía de guerra que ha vivido aquel país y la hasta ahora no resuelta transición de las estructu-

${ }^{5}$ Ejemplo parcial de ello, y en lo que al efecto migratorio concierne, es el reciente anuncio del Servicio de Inmigración y Naturalización (SIN) del gobierno de Estados Unidos en el sentido de que "decidieron no proceder con las peticiones de asilo político de refugiados nicaragüenses, 'hasta que asuma el poder el nuevo gobierno de Violeta Chamorro'". Excélsior, 23 de marzo de 1990. 


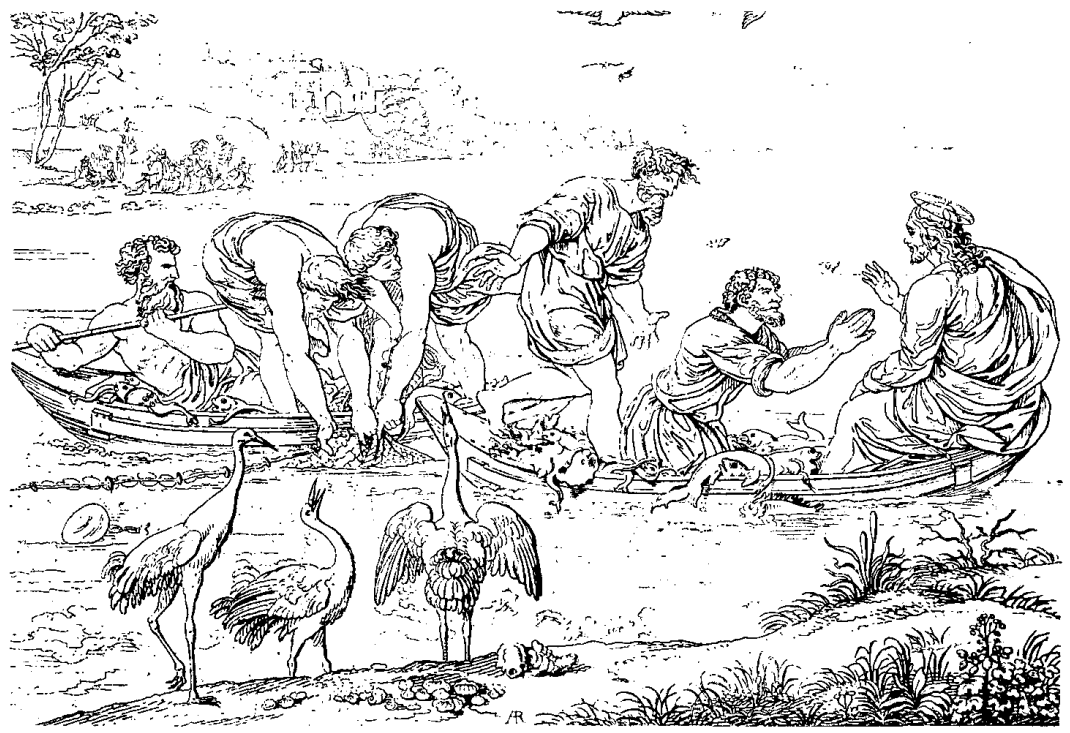

ras de poder a partir de los resultados electorales favorables a la oposición legal, entre otros factores, no permiten, por ahora, establecer el rumbo que tomará aquella nación ni tampoco necesariamente la posición que adoptará en el contexto de las relaciones internacionales.

Por otra parte, en los casos de Guatemala y El Salvador, el conflicto político tampoco muestra una tendencia clara hacia su resolución. Los llamados al diálogo como vía para dirimir el enfrentamiento han sido -hasta la fecha- poco fructíferos. Nuevos intentos en esta dirección se están produciendo en estos momentos, pero generar expectativas a partir de tales iniciativas es aún prematuro. Lo que es cierto es que, cualquier principio de solución a este nivel, es poco probable que permita mejorar sustancialmente y a corto plazo la deteriorada situación económica de cada uno de esos países.

Esta incertidumbre, al menos desde nuestras preocupaciones, nos obliga a considerar que, al menos por un buen tiempo, los factores que han provocado los intensos movimientos de población presenciados en los últimos años, pueden continuar operando aunque se modifiquen parcialmente algunas de sus características. En este sentido, las características no solamente sociales sino también geográficas de México seguirian siendo favorables, tanto para que continúe siendo lugar de destino como de paso 
de los flujos migratorios. Su situación de mayor desarrollo relativo y su vecindad geográfica son factores que contribuirán a este papel.

EL PAPEL Y TIPO DE MIGRACIONES EN LAS RELACIONES FRONTERIZAS CON CENTROAMÉRICA

En otros trabajos hemos descrito in extenso la larga tradición migratoria de trabajadores temporales guatemaltecos que concurren anualmente a laborar en las cosechas de productos agrícolas en la región del Soconusco, Chiapas. De ellos, el café es el cultivo que ha utilizado en mayor medida esta fuerza de trabajo y, en la actualidad, puede afirmarse sin temor a equivocarse que sin su presencia sería imposible, en las condiciones presentes, llevar a término el comercio del grano en el mercado internacional y, por lo tanto, generar ese importante cúmulo de divisas tan necesarias para la economía nacional.

En ese sentido, existe una tradición migratoria en la región del Soconusco, por la que se ha afirmado la más intensa relación fronteriza con el vecino país de Guatemala. Al igual que en otros contextos limítrofes, en esta región existen vínculos comerciales, culturales, familiares, sociales, etc., a los cuales se suman los de carácter histórico, derivados de un pasado común que se remonta no sólo a la dominación colonial sino incluso a la época prehispánica. Así, durante mucho tiempo, ha existido un intercambio que ha variado en matices, dependiendo de las particularidades de los momentos históricos y del estado de las relaciones. En ese marco, también durante muchos años han ocurrido diversos flujos migratorios, tanto de carácter más o menos permanente $y$ que tienen como destino la región fronteriza, como de paso hacia otros territorios.

Sin embargo, durante la última década esta dinámica se modificó sustancialmente. Los flujos se intensificaron y diversificaron en calidad y extensión de sus efectos. A una frontera relativamente delimitada por la tradición de los vínculos y los flujos, se opuso ahora una nueva, extensa y poco definida, debido a la baja clensidad de población, el relativo bajo perfil de explotación de sus recursos naturales y la escasa presencia de autoridades e instituciones. La llegada masiva de refugiados guatemaltecos y el incremento de las -llamadas por muchosmigraciones "económicas" atrajcron la atención de propios y extraños.

La frontera sur apareció de pronto en el escenario nacional y se convirtió en tema de preocupación y de debate. A ello contribuyeron las posiciones de sectores internos lógica. mente preocupados por la situación del país, aunque también por la seguridad y bienestar de los refugia. dos. Pero también operó una campaña ideológica de prevención ante la posible "extensión, contaminación y propagación" de las luchas revolucionarias centroamericanas, campaña principalmente concebida y orquestada en el exterior del país. La inexistente política explícita en materia de inmigración internacional posibilitó la adopción de medidas casuísticas, a ve- 
ces no sólo inapropiadas, sino propicias para que se produjeran excesos, arbitrariedades, abusos y vejaciones. El caso de los refugiados también evidenció las limitaciones de un marco jurídico e institucional adecuado para enfrentar la situación.

Paulatinamente, el Estado mexicano, con la colaboración de organismos internacionales y no gubernamentales, ha encauzado la atención de los migrantes y su permanencia en territorio nacional. De la etapa de prestación de servicios inmediatos (salud, vivienda, alimentación, etc.) se tuvo que pasar a resolver los problemas que demanda una estancia más prolongada. Procesos de escolarización, de atención preventiva en salud y, sobre todo, de incorporación a una vida productiva son ahora $-y$ mientras permanezcan en territorio nacional- 6 los principales requerimientos

${ }^{6}$ El horizonte temporal de su permanencia es incierto. Las presiones para el retorno han provenido básicamente del gobierno guatemalteco. No obstante, el número de personas que han regresado es insignificante con relación al total de refugiados reconocidos y asentados en los campamentos atendidos por COMAR y ACNUR ubicados en los estados de Campeche, Chiapas y Quintana Roo. Puede afirmarse que, en ese sentido, las cifras totales de alrededor de 45000 refugiados permanecen constantes. Pero además existe un número indeterminado de refugiados no reconocidos, disperso en un amplio territorio, principalmente del estado de Chiapas. Sin embargo, la posición de la mayoría de los refugiados es de no retornar en tanto el gobierno y el ejército guatemaltecos no satisfagan una se. rie de condiciones que han fijado como esenciales para reasentarse en sus lugares de origen,

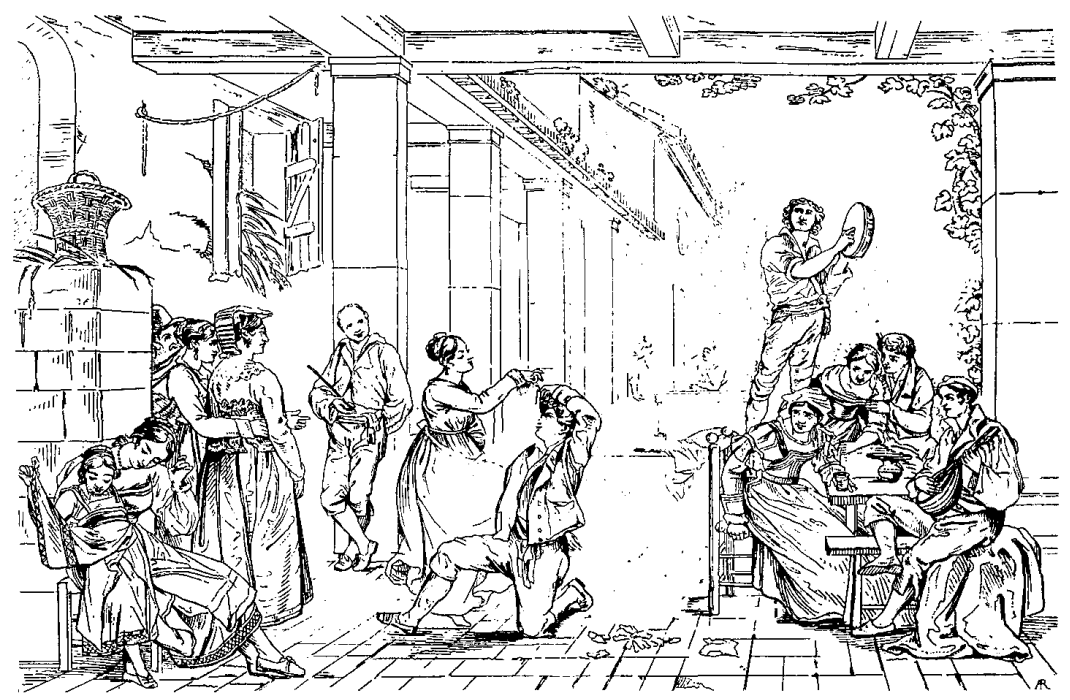


de atención. Ello ha implicado un profundo conocimiento no sólo de sus características sociodemográficas, sino sobre todo de su perfil y bagaje culturales que constituyen elementos de sustento básico para una perspectiva de asentamiento integral.

Por otro lado, la frontera chiapaneca ha intensificado su condición de "corredor de paso" de flujos de migrantes que se dirigen a otras zonas del territorio nacional, o bien, que se dirigen a la frontera norte con el propósito de cruzarla para alcanzar el "nuevo Dorado": Estados Unidos. Esta intensa movilidad, experimentada particularmente durante los últimos años y que sostenemos que tiene sus causas en la profundización de la crisis generalizada, se ha convertido en un elemento perturbador en la región, cuyos efectos reales son efectivamente poco conocidos. Hemos insistido en otros trabajos en que los ámbitos fronterizos son terrenos propicios para la proliferación de mitos profundamente xenofóbicos, puesto que cumplen un doble papel: por una parte, contribuyen a generar actitudes y a que se emprendan acciones que entorpezcan o reduzcan la migración, con efectos positivos para algunos sectores de poder, ${ }^{7}$ $y$, por la otra, sirven como elementos distractores ofuncionales para la reso-

así como que se les garantice la protección de su vida, su integridad personal y de los escasos bienes materiales que poseen.

7 Existen abundantes ejemplos en otras latitudes del planeta en este sentido que ilustran cómo la persecución, el estigma y la condición de "ilegalidad" de los trabajadores migratorios contribuyen a deprinsir los salarios reales con las consecuentes ventajas para los empleadores. lución de conflictos locales, regionales e incluso nacionales, con orígenes y relaciones diferentes que poco tienen que ver con el fenómeno migratorio. ${ }^{8}$

\section{TENDENCIAS RECIENTES Y PERSPECTIVAS DE LA INMIGRACIÓN}

Uno de los componentes que también ha atraído la atención, no solamente de estudiosos del fenómeno migratorio sino también de los medios de comunicación y las dependencias involucradas en su tratamiento, es el de su cuantificación. Efectivamente, el carácter de mayoritariamente indocumentado e irregular del flujo hace difícil la precisión de su volumen. Pero es más, la extensión y diversificación recientes de los movimientos han rebasado la capacidad de control de los puestos fronterizos de la Dirección General de Servicios Migratorios de la Secretaría de Gobernación, orga-

8 En este sentido, es común la frecuencia y el sobredimensionamiento de los problemas sociales -como la delincuencia, el alcoholismo, la orogadicción, la prostitución, etc- - entre los grupos de migrantes. Es más, se les acusa de ser portadores de todos los males sociales, dejando entrever que si no ocurrieran las migraciones dichos fenómenos no existirían, lo cual es bastante alejado de la realidad. También se les acusa de ser transmisores de enfermedades endénicas, la mayor parte de las veces sin aportar pruebas de tal comportamiento; por eso, no resulta extraño que, en los últimos tiempos, incluso autoridades de salud hayan manifestado públicamente que los migrantes centroamericanos son portadores del SIDA, cuando sibemos que las principales fuentes de contaminación se encuentran más bien allende la frontera norte por las características del origen y el disurrollo de la enfermedad. 
nismo al que por ley le corresponde tal función. ${ }^{9}$

Hemos planteado en ocasiones anteriores que dicha preocupación es legítima por razones obvias. Lo que hemos señalado es que resulta improcedente que, por la presión de circunstancias, autoridades o comunicadores, sucumbamos a la tentación de externar cifras sin fundamento alguno. La proliferación indiscriminada de cantidades también tiene efectos en distintos ámbitos de la sociedad y puede satisfacer los más diversos propósitos. En todo caso, nuestra experiencia nos permite afirmar que, apenas en los últimos años se ha avanzado en la sistematización de los registros de algunos flujos de documentados, así como en el de las expulsiones de los indocumentados.

Señalamos arriba también que, en los años recientes, se ha expérimen. tado un incremento y una diversificación (en las características sociodemcgráficas de sus integrantes, en las modalidades, en las rutas, etc.) de los flujos. Apuntamos también que nuestra hipótesis de trabajo es que estos cambios obedecen a la extensión y profundización de la crisis de todo orden en los países de origen. Por esa razón, hemos argumentado acerca de

9 Los medios de comunicación dan cuenta de una intensa campaña de detencionẹs de migrantes indocumentados desplegada en los últimos tiempos. Sin embargo, llama la atención la frecuente participación activa de elementos de otros cuerpos de seguridad, con atribuciones distintas, pero sobre los cuales evidentemente no existe un control por parte de las autoridades competentes. Se ha denunciado que, en la mayoría de los casos, los abusos provienen precisamente de estos elementos. la insuficiente categorización de la tradicional dicotomía entre "migrantes económicos" y "migrantes políticos". Hemos dicho que las migraciones de centroamericanos de los ochenta, que se han dirigido a México y Estados Unidos principalmente, han puesto a prueba los enfoques teóricos que han operado en otras formaciones sociales y en otras circunstancias históricas. Es nuestra opinión que, en el caso presente, se hace cada vez más difícil dilucidar o tratar de encasillar en una de esas dos categorías al conjunto de la población migrante, que más bien parece mostrar una amplia gama de situaciones. Creemos que la principal evidencia de esta complejidad es el caso de los refugiados guatemaltecos, quienes emigraron forzosamente pero sin poder demostrar una persecución directa por causa de una creencia o una militancia política.

Por esa razón pensamos que el pa. norama actual de las migraciones se nos aparece mucho más complejo de lo que se nos presentaba en el pasado. Hoy, por ejemplo, a partir de los registros de los expulsados, ${ }^{10}$ encontramos que, si bien existe un alto porcentaje de migrantes indocumentados de origen rural (alrededor de un 33\%), la mayoría de ellos muestran antecedentes de procedencia urbana. Esta situación puede tener varias lecturas. Por una parte, esa relativamente elevada proporción de tra-

10 Hemos trabajado con los datos de las expulsiones (resultado de las detenciones) realizadas por las delegaciones regionales de la Dirección General de Servicios Migratorios de la Secretaría de Gobernación, correspondientes al año de 1988. 
bajadores del campo que recurren a la migración indocumentada, puede manifestar la existencia de factores que están obligando a tal tipo de solución de sobrevivencia a sectores que antes no acudían a ella. ${ }^{11}$ Por la otra, el pre. dominio relativo de una población urbana en el conjunto de los migrantes podría confirmar en principio nuestra hipótesis de que el grueso de este ripo de flujo lo forman personas con una experiencia de trabajo urbano, con un probable mínimo de escolaridad y calificación para el trabajo, sin saber en qué proporción se trate de desempleados, puesto que no se dispone de información en este sentido. ${ }^{12}$

Otro elemento que no puede escapar a nuestras consideraciones es que el incremento de desplazamientos bajo condiciones irregulares ha permitido que su operación se constituya en un negocio lucrativo para algunas personas. Efectivamente, la condición de indocumentado del flujo, su-

11 Lo planteamos como hipótesis, por cuanto no disponemos de registros históricos que permitan contrastar la evolución de la composición de los flujos. Además, pensamos que el deterioro de la situación del campo en los respectivos países de origen (no sólo en términos económicos -de empleo, producción, etc.-, sino también por la situación de guerra que se vive en algunas regiones) ha violentado de manera prácticamente forzosa este tipo de solución.

12 Las evidencias encontradas en el caso de las migraciones de mexicanos hacia Estados Unidos apuntan en dirección de un perfil de migrante de esta naturaleza. Contradice las apreciaciones de que se trata del resultado de un proceso masivo de expulsión de población del campo, de campesinos sin tierras, que no pueden ser absorbidos por las fuentes de empleo asalariado, urbano o rural. mada al desconocimiento del entorno en que ocurre, posibilita la proliferación de personas, e incluso instituciones organizadas que se benefician del proceso. A diferencia de los "enganchadores" y "contratistas" que han operado por largo tiempo en el reclutamiento de trabajadores agrícolas temporales, ${ }^{13}$ los denominados "polleros" constituyen la expresión de un sistema más o menos organizado, que lucra con la irregularidad, el desconocimiento y la indefensión de los migrantes que no tienen posibilidades de regularizar su desplazamiento, promoviendo la corrupción de diversos agentes locales.

\section{CONSIDERACIONES FINALES}

Este rápido recorrido por la que ha devenido en compleja situación de las corrientes migratorias que transitan por la frontera sur de México, especialmente durante los años recientes, debe generar una serie de inquietudes y reflexiones. Se trata de estimular la preocupación, no solamente de las dependencias que por ley son responsables de la atención del problema, sino

13 En un artículo de proxima publicación, señalamos nuestro hallazgo, derivado del trabajo de campo realizado para conocer la situación de estos trabajadores, en el sentido de que encontramos una tendencia a que, en el reclutamiento, disminuya la participación de los "enganchadores" (al menos en el grupo de los migrantes entrevistados), a persistir la presencia de los "contratistas" (como una todavia necesaria intermediación parcial con los emplea. dores grandes) y la mayor proporción de contrataciones directas (sobre todo, en el caso de los ejidatarios). 
también en los ámbitos de discusión política, de investigación académica, de orientación de la opinión pública y, por qué no, también en el de la sociedad civil en general. Creemos haber planteado que, en todos esos medios, existe un margen de participación y responsabilidad que tiene que ver con las percepciones, las actitudes y el trato de las personas que llegan a territorio mexicano.

Hemos reiterado una vez más el peligroso efecto de la difusión de creencias infundadas acerca de la presencia de extranjeros y sus efectos nocivos en los ámbitos culturales, sanitarios, sociales, políticos, económicos, etc. Una prensa responsable, una opinión pública crítica y una práctica de investigación sistemática y rigurosa, son elementos que pueden contribuir en la dirección apropiada para la tarea de la desmitificación, que de otra manera encuentra un caldo de cultivo para su difusión en el ámbito de la sociedad civil. De esa cuenta, el apoyo a la investigación científica de los diversos aspectos del fenómeno migratorio es un requisito fundamental porque permite sustentar un cambio de actitud y de tratamiento de los problemas que giran a su alrededor. Esta tarea será más viable y expedita con el apoyo y cooperación, tanto de las de. pendencias responsables como de los medios de comunicación.

También se señaló que la ausencia de políticas explícitas propicia, entre otros efectos, la atención causística y, a veces arbitraria, de los flujos migratorios, especialmente de aquellos que tienen el carácter de indocumentados. México ha exigido el trato justo de sus migrantes a Estados Unidos y ha desplegado una amplia campaña para velar porque se respeten sus derechos elementales. De la misma manera y para ser coherentes con tal posición, es necesario buscar mecanismos de ar. ticulación entre políticas y prácticas de información y protección adecua. das dirigidas tanto a emigrantes como a inmigrantes.

En este mismo sentido, esa relativa ausencia también ha permitido la participación de elementos ajenos a los que por ley corresponde regular y controlar las corrientes migratorias. Generalmente, dichas instancias gubernamentales no son conscientes de todos los preceptos y actitudes (y casi podríamos descargarlos de esa responsabilidad) que deben guardar hacia una población específica como es el caso. Pero lo que es peor, su condición de autoridad formal, sumada al desconocimiento por parte de los extranjeros de los marcos legales e institucionales vigentes en el país, les ha permitido, en algunos casos, ejercer acciones arbitrarias y lesivas de los derechos. Ello sugiere la necesidad de regular drásticamente la participación de dependencias en un campo bien definido de actuación y, por otra parte, desplegar una amplia campaña de información para que los migrantes conozcan y ejerzan sus derechos.

En el caso de las dependencias legítimamente autorizadas para actuar, es importante apoyar los esfuerzos encaminados a capacitar y mantener actualizados a sus elementos -sobre todo a aquellos que tienen trato directo con los migrantes-, tanto en la impartición de conocimientos en ma- 
teria legal y de convenciones internacionales, como la de correcta aplicación de los principios de política migratoria y de aplicación de las normas vigentes. Pero la educación no basta por sí misma para enmendar la situación; es preciso generar nuevas actitudes por la vía del ejemplo, incrementar la vigilancia y generar los re. cursos necesarios para que cumplan adecuadamente con su función.

Es evidente que el apego y la observancia de los derechos fundamentales del hombre debe constituir una preocupación general por lo que en sí misma implica; pero también se tiene conciencia de que su cumplimiento se ha convertido cada vez más en un tema de atención de la comu. nidad internacional, así como también en un elemento clave para la negociación bilateral en materia de emigración de mexicanos hacia Estados Unidos.
En materia de política internacional, la posición del gobierno mexicano debiera ser fortalecida en lo que se refiere a la búsqueda de la pacificación por la vía del mejoramiento de las condiciones de los pueblos. Ello supone encaminar esfuerzos orientados a promover transformaciones sociales, para lo cual la cooperación internacional es apenas un ingrediente útil mas no suficiente, en tanto que su peso específico es incierto mientras no se garantice una reorientación de los recursos en beneficio de los sectores más necesitados. Sin embargo, en lo inmediato, debiera también promoverse enérgicamente que se cumplan los acuerdos regionales que México ha promovido con otros países, sobre todo, en lo que se refiere al necesario diálogo de las partes en conflicto como vía de solución al conflicto político. 


\section{SECUENCIA}

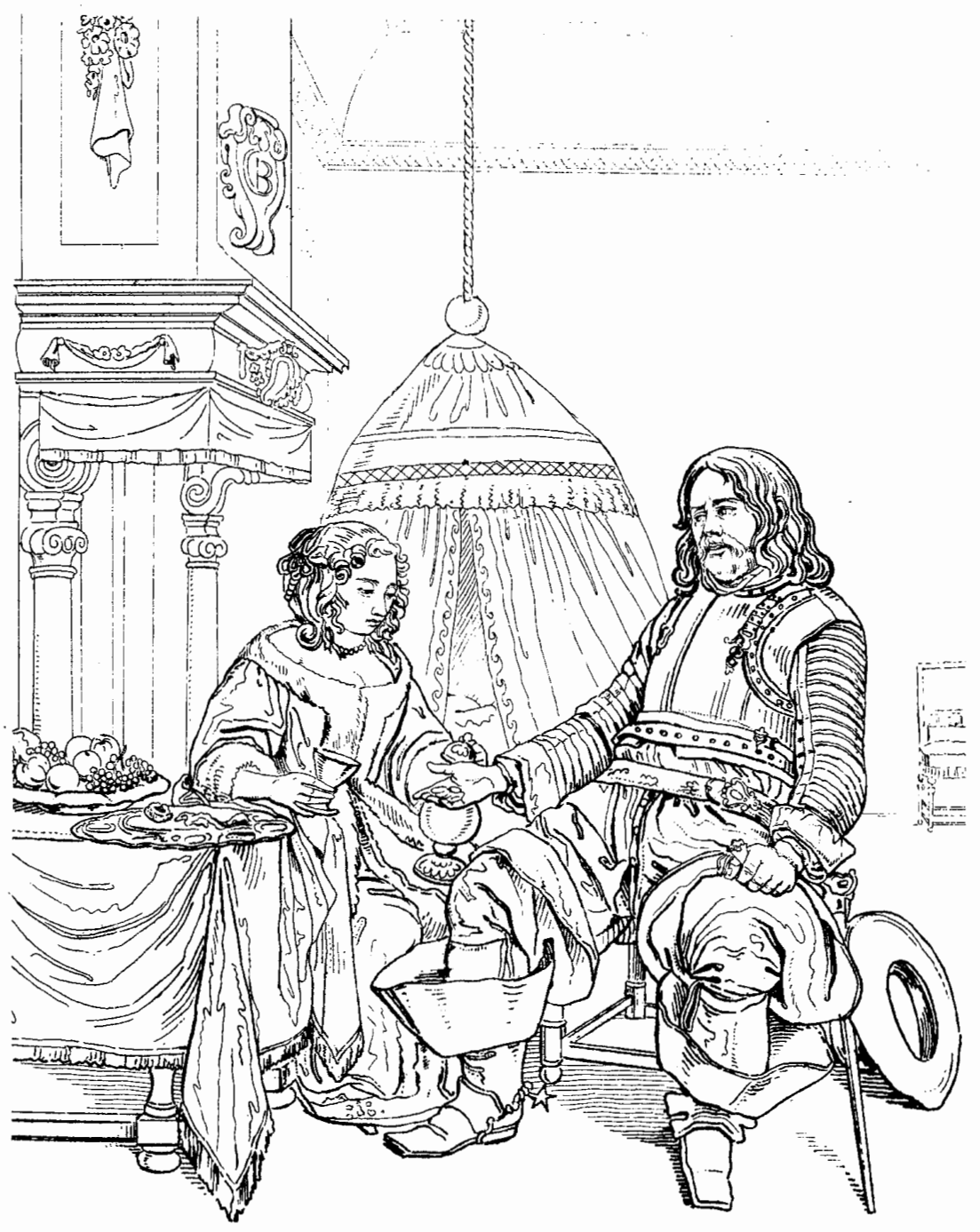

